\title{
Patrimônio histórico e história local em Cabo Frio: políticas de patrimonialização e construção de memórias
}

\author{
Patrimonio histórico e historia local en Cabo Frio: \\ políticas de patrimonio y construcción de memorias \\ Historical heritage and local history in Cabo Frio: \\ heritage policies and memory building
}

AUTOR

\section{André Luiz Garrido Barbosa*} garrido-andre@ hotmail.com

\section{* Doutorando pelo} programa de pósgraduação em História Social da Faculdade de Formação de Professores da Universidade Estadual do Rio de Janeiro (UERJ, Brasil).

\section{RESUMO:}

A presente reflexão tem por base o estudo de bens tombados pelo Instituto do Patrimônio Histórico e Artístico Nacional (IPHAN) na cidade de Cabo Frio (Rio de Janeiro, Brasil). Essa escolha se justifica porque esses bens são referenciais simbólicos relacionados à história local por parte do reconhecimento de uma autarquia do poder público, que tem como responsabilidade a preservação do Patrimônio Cultural Brasileiro, cabendo à mesma proteger e promover os bens culturais do país para as gerações do presente e do futuro. $O$ fato de Cabo Frio ser uma cidade estruturada no período colonial e ter um conjunto de bens arquitetônicos e elementos naturais que datam desse período contribuiu para que o IPHAN, uma autarquia federal que responde pela preservação do Patrimônio Cultural Brasileiro, viesse a tombar, em 1967, por meio do IPHAN, seu conjunto paisagístico, composto por monumentos e espaços públicos. 0 trabalho discutirá como as políticas de preservação patrimoniais analisadas fazem parte de um projeto de atribuição de valores em que se priorizou a seleção de bens edificados ligados ao passado colonial, procurando vincular esses fragmentos do passado com o presente, dentro de uma perspectiva de valorização de um discurso nacionalista, entremeado por disputas de memórias em torno dos diversos agentes envolvidos no processo.

\section{RESUMEN:}

La presente reflexión se basa en el estudio de los bienes catalogados como de interés cultural por el Instituto del Patrimonio Histórico y Artístico Nacional (IPHAN) en la ciudad de Cabo Frío (Río de Janeiro, Brasil). La elección se justifica por el hecho de que estos bienes son referencias simbólicas vinculadas a la historia local, reconocidos por una autoridad pública, responsable de la preservación del Patrimonio Cultural Brasileño, y a la que corresponde la protección y promoción de los bienes culturales del país para las generaciones presentes y futuras. El hecho de que Cabo Frío fuera una ciudad estructurada en el período colonial y tuviera un conjunto de bienes arquitectónicos y elementos naturales que se remontan a ese período contribuyó a que el IPHAN, una autarquía federal que se encarga de la preservación del patrimonio cultural brasileño, reconociera y catalogara en 1967 a través del IPHAN, su complejo paisajístico, compuesto por monumentos y espacios públicos. En el trabajo se discutirá cómo las políticas de preservación del patrimonio analizadas forman parte de un proyecto de atribución de valores, en el que se ha dado prioridad a la selección de los bienes construidos vinculados al pasado colonial, intentando vincular estos fragmentos del pasado con el presente, dentro de una perspectiva de valoración de un discurso nacionalista, veteado por las disputas de memorias en torno a los distintos agentes implicados en el proceso. 


\section{ABSTRACT:}

This reflection is based on the study of property listed by nstitute of National Historical and Artistic Heritage (IPHAN) in the city of Cabo Frio. This choice is justified by the fact that these properties are symbolic references related to the local history by the recognition of a public authority, which is responsible for the preservation of the Brazilian Cultural Heritage, being responsible for protecting and promoting the cultural assets of the country for present and future generations. The fact that Cabo Frio is a city structured in the colonial period and has a set of architectural assets and natural elements that date back to that period contributed to the IPHAN, a federal autarchy that is responsible for the preservation of the Brazilian Cultural Heritage, list in 1967, through IPHAN, its landscape set, composed of monuments and public spaces. This work discusses how the heritage preservation policies analyzed are part of a value assignment project in which priority was given to the selection of built assets linked to the colonial past, seeking to link these fragments of the past with the present, within a perspective of valuing a nationalist discourse, interspersed with disputes of memories around the various agents involved in the process. 


\section{Da degradação à monumentalização: processos de patrimonialização em Cabo Frio}

A cidade de Cabo Frio (Rio de Janeiro, Brasil), fundada pelos portugueses em 1616, como a Vila de Santa Helena de Cabo Frio, teve como atividade econômica inicial a exploração de paubrasil. Local estratégico para os portugueses no início do processo de colonização do litoral brasileiro, a região foi alvo da cobiça dos franceses, expulsos tempos depois pelo português Constantino Menelau, com ajuda de Mem de Sá e índios aliados (Beranger, 2003).

No decorrer do século XVII, Cabo Frio foi alçada à categoria de cidade, recebendo regimento militar e judicial. Teve como destaque a construção do prédio da Câmara Municipal e da Igreja de Nossa Senhora da Assunção. Com o passar do tempo, Cabo Frio foi se destacando no cenário econômico regional como grande produtor de sal, sendo esse produto o carro-chefe da economia local (Ribeiro, 2017).

Por ser uma cidade estruturada no período colonial, além de apresentar um conjunto de bens arquitetônicos e elementos naturais que datam desse período, contribuiu para que o Instituto do Patrimônio Histórico e Artístico Nacional (IPHAN), autarquia federal que responde pela preservação do Patrimônio Cultural Brasileiro, viesse a tombar, em 1967, seu conjunto paisagístico composto por monumentos e espaços públicos'.

Dentre os bens tombados pelo IPHAN, entre 1956 e 1957, encontram-se a Capela de Nossa Senhora da Guia (o tombamento abrange o Morro da Guia, onde está situada a capela), Convento e Igreja de Santa Maria dos Anjos, Capela e Cemitério da Ordem Terceira de São Francisco (cruzeiro e adro fronteiro, e o Largo de Santo Antônio até a orla do canal), Forte de São Matheus (inclusive o penedo em que ele se assenta e toda a ponta da praia), faixa do litoral situada entre a Av. Parque Litorâneo e o mar, além do Morro do Telégrafo, entre outras áreas ${ }^{2}$. Essas construções são predominantemente do período colonial, quando a cidade de Cabo Frio foi estruturada a partir de disputas envolvendo portugueses, franceses e indígenas, e quando foi fundada a Vila de Santa Helena de Cabo Frio, em 1616.
PALAVRAS-CHAVE História; memória; patrimônio

histórico; história de Cabo Frio.

PALABRAS CLAVE

Historia; memoria; patrimonio

histórico; historia de Cabo Frio.

KEYWORDS

History; memory; historical heritage;

Cabo Frio history.

Recibido: $16 / 03 / 2020$

Aceptado: 06/10/2020

Considerando o patrimônio histórico como todo legado material e imaterial que tenha importante significado e relevância histórica para uma sociedade ou grupos sociais, podemos considerar os bens tombados, dentro da perspectiva de Pierre Nora (1993), como lugares de memória. Dessa forma, os bens tombados para preservar aquela memória perdem seus significados originais e passam a ser ressignificados a partir dos usos que serão dados a eles, como monumentos a serem reverenciados.

Os lugares de memória são, antes de tudo, restos. A forma extrema onde subsiste uma consciência comemorativa numa história que a chama, porque ela a ignora. É a desritualização de nosso mundo que faz aparecer a noção (...) Os lugares de memória vivem do sentimento que não há memória espontânea, que é

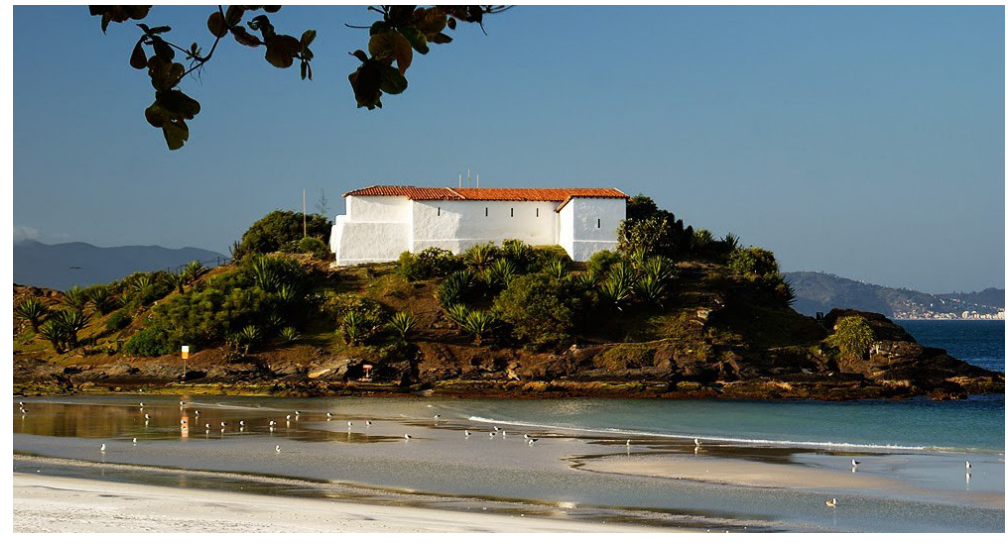

Imagem 1. Forte São Mateus em Cabo Frio.

Fonte: [http://cabofrioby3005.blogspot.com/2014/05/forte-sao-mateus.html]. 
preciso criar arquivos, que é preciso manter aniversários, organizar celebrações, pronunciar elogios fúnebres, notariar atas, porque essas operações não são naturais. São lugares, com efeito nos três sentidos da palavra, material, simbólico e funcional, simultaneamente, somente em diversos graus. Mesmo um lugar de aparência puramente material, como um depósito de arquivos, só é lugar de memória se a imaginação o investe de uma aura simbólica (Nora, 1993, pp. 12-13; p. 21).

Para que a preservação desse bem patrimonial e sua manutenção entre a coletividade na qual está inserido seja efetiva e permanente, é necessário que seja despersonalizado de suas características originais e possa, segundo Manoel Salgado, ser ressignificado, por meio da produção histórica.

O patrimônio é, portanto, resultado de uma produção marcada historicamente. É ao fim de um trabalho de transformar objetos, retirando-lhes seu sentido original, que acedemos à possibilidade de transformar algo em patrimônio. Adjetivar um conjunto de traços do passado como patrimônio histórico é mais do que lhes dar uma qualidade, é produzi-los como algo distinto daquilo para o qual um dia foram produzidos e criados (Salgado, 2012, p. 100).

Esses processos de desritualização, ressignificação e retirada de seu sentido primordial nos bens tombados pelo IPHAN em Cabo Frio acontecem em parte no momento em que as edificações deixaram de ser utilizadas para suas finalidades originais. Como no caso do Forte São Matheus, que deixa de ser utilizado para fins defensivos, ou o Convento Franciscano, que se tornou Museu de Arte Sacra. Vale lembrar que, no caso desses bens, esse processo ocorreu muito antes do tombamento, isto é, quando eles sofriam processo de degradação ou desvirtuamento de finalidade.

Ao referenciar a importância do patrimônio histórico como lugar de memória em que se procura criar uma identidade social, um passado em comum entre os indivíduos de certa localidade, Paulo Cesar Tomaz ${ }^{3}$ destaca que

Ao se contemplar um espaço de relevância histórica, esse espaço evoca lembranças de um passado que, mesmo remoto, é capaz de produzir sentimentos e sensações que parecem fazer reviver momentos e fatos ali vividos que fundamentam e explicam a realidade presente. Essa memória pode ser despertada através de lugares e edificações, e de monumentos que, em sua materialidade, são capazes de fazer rememorar a forma de vida daqueles que no passado deles se utilizaram. Cada edificação, portanto, carrega em si não apenas o material de que é composto, mas toda uma gama de significados e vivências ali experimentados (Tomaz, 2010, p. 2).

Dominique Poulot (2012), ao tratar da expansão do patrimônio como elo social que mobiliza indivíduos e instituições públicas e privadas para a conservação de heranças materiais e imateriais, ao qual podemos entender por meio de conjuntos materiais, saberes, valores e regimes de sentido, evidenciará que a aplicação deste campo de estudo produzirá uma razão própria na produção de sentido e de inteligibilidade.

Nisso, o patrimônio parece constituir um campo de aplicação privilegiado para reexaminar três questões sob o ângulo da circulação social: a do olhar erudito sobre obras e objetos materiais; a da historicização de uma sociedade e, de forma mais geral, de

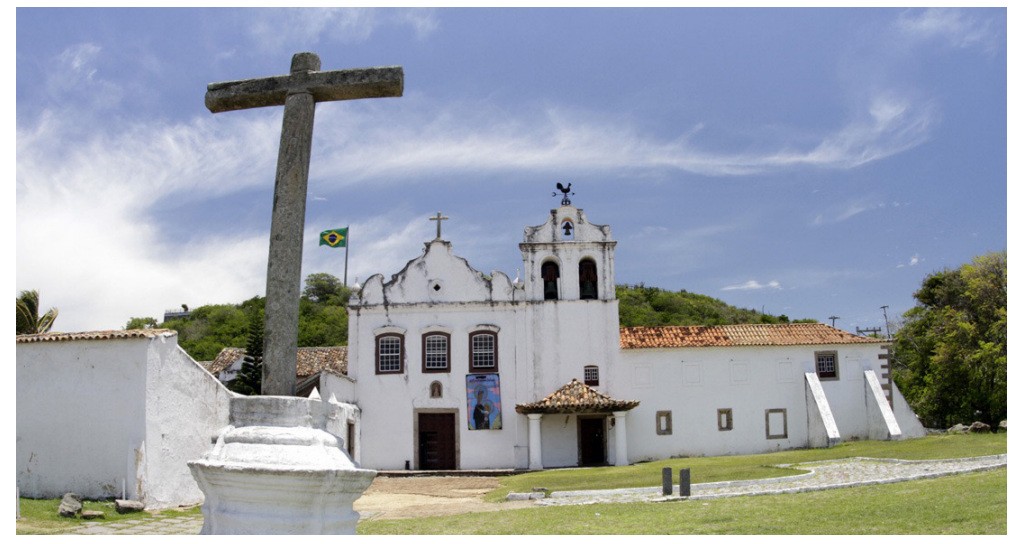

Imagem 2. Convento Franciscano Nossa Senhora dos Anjos/Museu de Arte Religiosa Tradicional.

Fonte: [http://mapadecultura.rj.gov.br/manchete/convento-de-nossa-senhora-dosanjos]. 
sua relação com "regimes de historicidade"; e, por fim, a da ética e da estética que dela decorrem ou à qual estão ligadas (a exemplaridade e a adesão, mas também a emancipação ou a denegação) ( Poulot, 2012, p. 32).

A valorização do patrimônio, como bem, e a sua própria conceituação constituir-se-ão a partir do contexto da Idade Moderna na Europa. Nessa época, a literatura artística procura exaltar uma cidade ou nação e a preservação de bens a eles associados. No século XIX, além das preocupações preservacionistas e de manutenção de uma memória e uma tradição, ligadas à emergência dos Estados-nações, percebeu-se uma progressiva instauração de um academicismo de conservação e restauração patrimonial. Ao longo do século XX, a noção de conservação ${ }^{4}$ passou a apresentar uma representação de historicidade ao tratar o patrimônio como um resquício do passado no presente. Dessa forma, houve uma ampliação do próprio conceito de patrimônio que deixará de ter, como prerrogativa, a conservação de bens materiais, passando a valorizar também a conservação de recursos culturais imateriais (Poulot, 2012).

Resta considerar, em seguida, as construções patrimoniais como outros tantos "modos apropriados" de tratar o passado, como outros tantos estilos - o estilo encarnando uma "noção de perspectiva histórica" (Guinzburg, 1998, p. 120), segundo a formulação luminosa de Carlo Ginzburg. Exposições recentes consagradas, ora a atores da patrimonialização monumental - para além dos grandes iniciadores Mérimée e Viollet-le-Duc, que são casos de escola -, ora a fundadores de museus, ora, por fim, a inventores de sítios arqueológicos, mostram o quanto esses episódios foram outros tantos estilos significativos de regimes materiais de temporalidade. Essa perspectiva, cuja especificidade decorre da adoção de um ponto de vista da recepção, é suscetível de se estender a formas de exposição, de encenação, de representação de um passado material (em particular no museu) que dão lugar a esse mesmo sentido de "patrimonialidade" ( Poulot, 2012, pp. 41-42).

Procurando evidenciar a importância do patrimônio histórico na sociedade contemporânea e os seus diversos usos pelo poder público ou por instituições culturais preservacionistas de um determinado tipo de memória, Daher (2012) destaca que

É certo que se possa falar, hoje, com Dominique Poulot, de "patrimônio" como uma disciplina ou como um tipo de administração voltada para a promoção de tradições, memórias e lugares, e mobilizada tanto para a produção de saberes quanto para as comemorações cívicas e o comércio de produtos, como os turísticos. Em todas essas práticas se inscreve a necessidade de preservação, inegavelmente ligada à busca da autenticidade de uma herança coletiva. Nesse sentido, ainda segundo Poulot, patrimônio tornou-se hoje, no Ocidente, sinônimo de laço social pela mobilização do poder público através das instituições culturais e de leis cada vez mais amplas que regulam a necessidade de conservação diante da realidade da destruição e da iconoclastia (Daher, 2012, p. 117).

François Hartog ressalta que a preocupação de preservação do patrimônio histórico a partir do século XX tem como uma de suas preocupações a dinâmica preservacionista, procurando criar uma ligação entre passado e presente, evocando esse passado, por meio da tentativa de retomar a emoção de uma vivência pretérita, o que possibilita criar um vínculo entre os homens do tempo presente e aquele passado legitimado.

O fato de que patrimônio e temporalidades estejam indissoluvelmente ligados é uma evidência, já que o patrimônio é a reunião de semióforos criada por uma sociedade, em um dado momento (e por um momento). Eles traduzem então o tipo de relação que uma sociedade decide estabelecer com o tempo. O patrimônio torna visível, expressa uma certa ordem do tempo, no qual a dimensão do passado conta. Trata-se, porém, de um passado do qual o presente não pode ou não quer se desligar completamente. Que se trate de celebrá-lo, imitá-lo, conjurá-lo, de extrair prestígio dele ou apenas de poder visitá-lo (Hartog, 2013, p.107).

A partir dessa percepção do patrimônio histórico, como algo que está relacionado à preservação de um passado e que está (ou é) associado a memórias de caráter individual ou coletivo, além de sua própria 
legitimação como um bem cultural contextualizado a um momento histórico em que foi criado, o patrimônio é historicamente construído, estando sujeito, portanto, a uma historicidade própria.

A preservação do patrimônio material e natural da cidade de Cabo Frio segue na lógica de se preservar um bem que tem ou possa ser atribuída uma relação de memória material, institucional e coletiva com a comunidade em que está relacionada, por meio do seu uso ao longo do tempo e de sua possível representatividade material e simbólica.

Cumpre ressaltar, pois, que a análise entre as aproximações, distâncias e transposições de narrativas entre a patrimonialização promovida pelo IPHAN em Cabo Frio e a produção de uma memória histórica, legitimada por um órgão oficial do governo e que promove uma construção de sentido, permanência e seleção do que deve ser enquadrado como memória oficial, estão dentro da perspectiva do uso do conceito de enquadramento de memória trabalhado por Michael Pollak (1989).

Em artigo publicado na revista Estudos Históricos, Pollak trabalha com a problemática das disputas de memória entre as narrativas dos indivíduos, as instituições responsáveis pela preservação e manutenção de uma narrativa de memória que procura legitimidade histórica e uma memória oficial ligada a algum grupo político que esteja no poder e que queira salientar ou ocultar alguns tipos de memórias ${ }^{5}$.

Segundo Pollak (1992), a memória é um fenômeno individual que abrange a todos os indivíduos de maneira singular e pessoal, estando relacionado às suas experiências e a leituras de mundo. Além disso, é um fenômeno coletivo e social, em que as experiências compartilhadas ou marcas identitárias entre os sujeitos, promovem uma aproximação ou uma troca de visões de mundo, entre as diversas narrativas de um mesmo evento pretérito.

A priori, a memória parece ser um fenômeno individual, algo relativamente íntimo, próprio da pessoa. Mas Maurice Halbwachs, nos anos 20-30, já havia sublinhado que a memória deve ser entendida também, ou, sobretudo, como um fenômeno coletivo e social, ou seja, como um fenômeno construído coletivamente e submetido a flutuações, transformações, mudanças constantes (Pollak, 1992, p. 201).

Constituindo um importante instrumental na preservação de informações do passado e servindo como ferramenta para a elaboração de uma narrativa histórica sobre um determinado passado, a problematização do uso da memória no trabalho do historiador otimiza a pluralidade das fontes históricas, além de permitir leituras diversificadas sobre o passado.

O uso da memória como uma das fontes históricas a serem utilizadas pelo historiador tem como um dos elementos problematizadores a participação na formação ou a permanência de identidades compartilhadas de um ou mais grupos sociais ou instituições, de maneira a ter uma consciência de pertencimento de grupo e perpetuação de hábitos para outras gerações por meio da participação direta ou indireta dos eventos pretéritos (Candau, 2014).

Pierre Norra, ao tratar da tensão que envolve memória e história, bem como suas implicações na produção da narrativa histórica, procura delimitar as fronteiras entre esses elementos e o processo de dessacralização da memória. Segundo ele, nesse processo o historiador, ao praticar uma operação intelectual laica e crítica, limita as possibilidades do uso da memória, que é fluída, menos formal e muito ligada às emoções.

A memória é vida, sempre carregada por grupos vivos e, nesse sentido, ela está em permanente evolução, aberta à dialética da lembrança, e do esquecimento, incosciente de suas deformações sucessivas, vulnerável a todos os usos e manipulações, suceptível de longas latências e de repentinas revitalizações. A História é a reconstrução sempre problemática e incompleta do que não existe mais. A memória é um fenômeno sempre atual, um elo vivido no eterno presente; a história, uma representação do passado. Porque é afetiva e mágica a memória não se acomoda a detalhes que a confortam; ela se alimenta de lembranças vagas, telescópicas, globais e flutuantes, particulares ou 
simbólicas, sensível a todas transferências, cenas, censura ou projeções. A história porque operação intelectual e laicizante, demanda análise e discurso crítico (Nora, 1993, p. 9).

A memória, seja por meio de relatos diretos ou indiretos dos indivíduos, ou por intermédio de monumentos que remontam as narrativas de eventos atribuídos ao passado, serve como recurso fundamental para a identidade social, remetendo à criação de um sentimento de ligação emocional, além de dar perenidade e vivacidade aos guardiões e mantenedores dessa memória, a partir de sua rememoração (Gonçalves, 1996).

A fim de entender o conjunto de regras que regem a escrita da história e como os indivíduos ou uma coletividade se instaura, desenvolve-se, percebe o tempo e o impacto dessa consciência de si e de uma comunidade na narrativa produzida por eles e pelos historiadores, utilizaremos o conceito de regime de historicidade (Hartog, 2013).

Por regime, quero significar algo mais ativo. Entendidos como uma expressão da experiência temporal, regimes não marcam meramente o tempo de forma neutra, mas antes organizam o passado como uma sequência de estruturas. Trata-se de um enquadramento acadêmico da experiência (Erfahrung) do tempo, que, em contrapartida, conforma nossos modos de discorrer acerca de e de vivenciar o nosso próprio tempo (Gonçalves, 1996, p. 96).

Em termos de regime de historicidade para o estudo dessa memória que é individual, coletiva e social, mobilizaremos o conceito de enquadramento de memória proposto por Pollak, ao ressaltar a utilização dos recursos da pesquisa histórica, da narrativa efetuada pelo historiador e das memórias que são selecionadas para serem preservadas, contribuirá para melhor compreendermos o porquê de algumas memórias serem mais valorizadas e ganharem estatuto de veracidade histórica (Pollak, 1988, 1992).

Assim, considerando que outros autores também tratam do uso da memória como recurso para o trabalho de historiadores e para a elaboração de um discurso histórico que dê conta de interpretar a realidade social, podemos utilizar desse instrumental teórico para embasar o referido trabalho e ajudar na compreensão histórica (Catróga, 2001; Costa, 2009; Huyssen, 2000; Hartog, 2013; Guimarães, 2012).

\section{Como tudo começou: um requerimento, dois processos e o tombamento}

O objeto desta reflexão é o processo de patrimonialização de bens da cidade de Cabo Frio. Esse ato teve início com a abertura de um processo de tombamento pelo Instituto do Patrimônio Histórico e Artístico Nacional (IPHAN) no ano de $1951^{6}$. Nesse ano, o Departamento Geográfico da Secretaria de Viação e Obras Públicas do Estado do Rio de Janeiro enviou um ofício ao então diretor do Serviço do Patrimônio Histórico e Artístico Nacional (SPHAN), demandando o tombamento do Morro da Guia, juntamente com o Convento e a Igreja presentes no local. Como argumento para o aludido tombamento, o requerente alegou que o Morro da Guia é, para cidade de Cabo Frio, o equivalente ao Pão de Açúcar para a Rio de Janeiro.

Em resposta a essa solicitação, o IPHAN iniciou o processo de tombamento ${ }^{7}$, estendendo os limites da área a ser preservada até as ruínas do Forte São Mateus. Como alegação, os responsáveis pelo ato defenderam a ideia de que os locais em que estão localizados esses monumentos eram unidades paisagísticas muito procuradas pelos turistas que visitavam a cidade.

Esse requerimento deu origem a dois processos (447-T-51 e 7575-T-65) ${ }^{8}$, que se complementam e que se arrastaram por décadas, passando por diferentes instâncias da burocracia estatal, com discussões sobre alguns dos principais desafios enfrentados na gestão do patrimônio da cidade, que vão desde a abertura do processo de tombamento na década de 1950, passando pela necessidade de definir os limites da área a ser tombada, de solucionar a escassez de recursos para manter as áreas de tombamento, indenizações a antigos proprietários ou ocupantes de algumas das áreas, as disputas de interesses econômicos e imobiliários locais com o crescimento desenfreado da cidade a partir da expansão do turismo na Região do 
Lagos na segunda metade do século XX e as dificuldades encontradas pelo IPHAN na preservação desses monumentos. Sobre estes, vale dizer, além do caráter histórico, também foram valorizados pela questão paisagística.

Observando essas problemáticas, percebemos três eixos importantes em relação a esses processos de tombamentos e que serão analisados dentro das possibilidades deste artigo. O primeiro ponto será a problematização sobre a preservação patrimonial desses bens, com forte ligação com o passado colonial português e que sofreram um processo de conservação por parte do IPHAN. Cumpre destacar que esse órgão buscou manter saberes, valores e regimes de sentido, com o objetivo de produzir uma inteligibilidade histórica a partir dessa memória que será preservada (Poulot, 2012; Gonçalves, 1996).

O segundo ponto a ser explorado diz respeito ao processo de enquadramento de memória efetuado pelo IPHAN. Esse instituto, responsável por chancelar os bens e saberes que são constituintes de um patrimônio histórico nacional, ao eleger alguns monumentos e paisagens como representativos de uma memória histórica local, bem como capazes de apresentar ligações com uma história nacional, tem como objetivo "enquadrar uma determinada memória, que passa a ser legitimada, como importante para a compreensão daquele passado e que irá sofrer a despersonificação de suas características originais” (Pollak, 1989, 1992).

O terceiro ponto a ser abordado neste artigo será a compreensão do processo de tombamento efetuado pelo IPHAN, como transformação desses monumentos em lugares de memória, com auxílio da produção de uma narrativa intelectual produzida pelos membros do instituto do patrimônio histórico que elegeu locais, bens e memórias atreladas a esses espaços como locais de produção de sentido histórico (Nora, 1993).

Assim, neste texto serão trabalhados os conceitos de patrimônio histórico, enquadramento de memória e lugares de memória, a fim de buscar compreender como o processo de tombamento, efetuado a partir da década de 1950, será capaz de ajudar na construção e preservação de alguns bens históricos na cidade de Cabo Frio, sem que houvesse uma maior participação dos moradores da cidade. Nesse sentido, acreditamos que a política de preservação se restringiu ao tombamento e à fiscalização dos bens imóveis, sem maior envolvimento da sociedade civil organizada em função de uma determinada concepção de política de preservação vigente à época.

Devemos considerar que, devido aos limites deste estudo, a gama enorme de documentos e o extenso período que os processos abrangem, focalizaremos a nossa análise no Forte São Matheus e no Convento Nossa Senhora dos Anjos.

\section{A constituição do Patrimônio Histórico a ser preservado: o que preservar, e para que preservar}

Em 06 de Junho de 1951, a Diretoria do Patrimônio Histórico e Artístico Nacional, por intermédio do seu diretor, Rodrigo Melo Franco de Andrade ${ }^{9}$, solicitou à Prefeitura Municipal de Cabo Frio o nome e os endereços dos proprietários de terrenos na área do Morro da Guia, onde se localizam o convento e a Igreja Santa Maria dos Anjos, assim como a Capela de Nossa Senhora da Guia ${ }^{10}$. No mesmo dia, o diretor do SPHAN, por meio do ofício no 779, comunicou ao diretor do Departamento Geográfico, que o SPHAN julgou procedente a solicitação desse departamento a respeito da inscrição do conjunto arquitetônico e paisagístico do Morro da Guia no livro de Tombo Histórico, como também no de Belas Artes, comunicando que, pelo parecer da divisão responsável por estudos e tombamentos, a inscrição no livro de tombo deve estender-se a ponta do forte.

Em resposta à consulta formulada no, citado ofício de V.S., cabe-me comunicar-lhe que esta Diretoria julga acertado e conveniente proceder à inscrição do referido conjunto, quer no Livro do Tombamento Histórico quer no das Belas Artes, dada a significação dos monumentos de arquitetura religiosa que o integram, ou sejam, o convento e igreja de Santa Maria dos Anjos e a capela de Nossa Senhora da Guia. 
No parecer da Divisão de Estudos e Tombamentos, a inscrição deve estender-se à Ponta do Forte, para abranger as ruínas do Forte de São Mateus, que formam com a área onde se acham localizados aqueles monumentos, uma unidade paisagística, tão procurada pelos turistas (Processo, n 447-T-51, p. 5).

No parecer da diretoria do SPHAN apresentado ao Departamento Geográfico, encontram-se como significantes para o tombamento dos monumentos selecionados sua arquitetura colonial e o fato de serem importantes objetos de visitação turística.

No Brasil, designou-se como patrimônio histórico e artístico nacional, basicamente, aquilo que foi classificado como arquitetura tradicional do período colonial, representante "genuína" das origens da nação. O passado resgatado não poderia jamais tratar do que fosse imediatamente anterior ao tempo presente que se queria negar - um quase presente -, e, nessa relação dada pela ruptura, era preciso que entre os dois acontecimentos não houvesse nenhuma causalidade. A escolha do que se pretendia identificar como constituinte da nação resultou na seleção de bens que representassem uma história remota e originária, inscrita num "tempo homogêneo e vazio", revelando a construção de uma história da nação fundada na possibilidade de construir heróis nacionais que deviam informar as ações no futuro e conter as diferenças no presente, distanciando-se dele. O processo de embelezamento dos monumentos, sua restauração e o enorme empenho em mantê-los conservados da deterioração corresponde à metáfora desse processo de "embelezamento" da história (Chuva, 2009, p. 48).

Desde a sua criação, o SPHAN teve como principais funções a seleção e a preservação de bens móveis, imóveis e conjuntos urbanos. Criado em 1937, durante o Estado Novo, em um momento de transformações políticas e institucionais, em que o Estado Brasileiro procurou ressignificar a identidade nacional, por meio de práticas que pudessem ligar o passado da Nação com o presente, o SPHAN tornou-se o órgão federal responsável por produzir uma narrativa que legitimasse fragmentos do passado, selecionados, catalogados e direcionados por esse órgão da burocracia estatal em semióforos representativos de uma identidade que utiliza parâmetros unificadores para produção de sentido pela chancela de patrimônio (Chuva, 2009; Gonçalves,1996).

Historicamente atribuída com exclusividade ao Estado, a ação de preservação dos bens culturais confere a determinados bens um caráter simbólico de emblema representativo da nacionalidade, cuja legitimidade é conquistada pela ritualização das práticas de preservação então instauradas, estabelecendo, por meio desses bens culturais, uma continuidade em relação a um passado remoto (Chuva, 2009, p. 33).

A patrimonialização efetuada pelo DPHAN, posteriormente denominado IPHAN, em Cabo Frio nos anos de 1950 segue a uma lógica que acompanha essa autarquia estatal desde a sua criação, a da ênfase no tombamento de bens que estejam maciçamente ligados ao passado colonial, edifícios monumentais que tenham representatividade local a partir do olhar dos responsáveis técnicos que, na época, eram em grande parte ligados à área de arquitetura e que apresentaram, em suas escolhas, a preocupação em manter uma memória história edificada (Chuva, 2009).

Vale dizer que a escolha do conjunto arquitetônico e paisagístico que inclui o Convento Nossa Senhora dos Anjos, o Forte São Matheus e áreas contíguas obedeceu

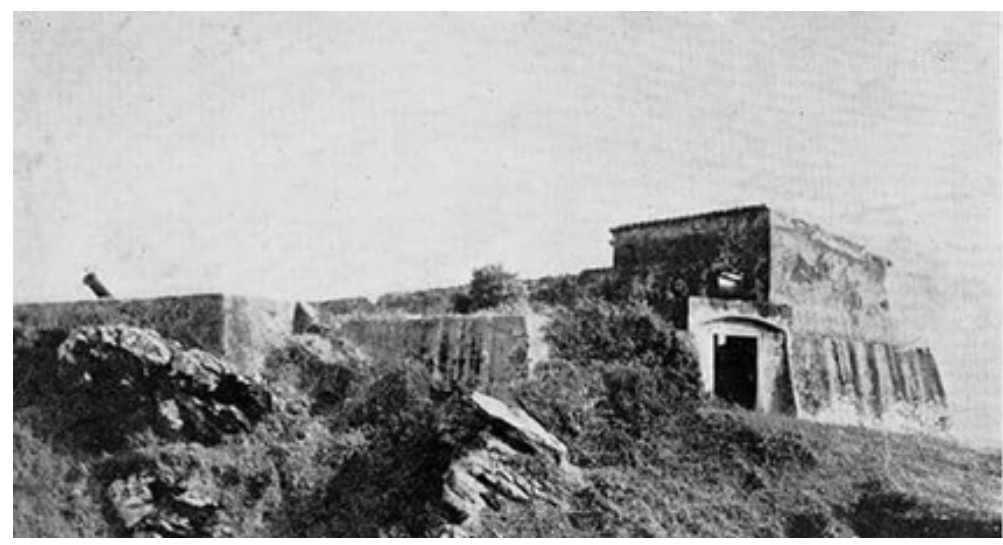

Imagem 3. Ruínas do Forte São Mateus em 1938.

Fonte: [https://br.pinterest.com/pin/442689838363773359/]. 
a essa tendência de valorização dos monumentos com ligação ao passado colonial. Como é possível observar, buscou-se criar um elo entre o passado, servindo de ponte para construção de uma identidade nacional por esse órgão da burocracia estatal, assumindo a função de estreitar e construir pontes entre diferentes temporalidades.

Assim como a identidade de um indivíduo ou de uma família pode ser definida pela posse de objetos que foram herdados e que permanecem na família por várias gerações, também a identidade de uma nação pode ser definida pelos seus monumentos aquele conjunto de bens culturais associados ao passado nacional. Estes bens constituem um tipo especial de propriedade: a eles se atribui a capacidade de evocar o passado e, desse modo, estabelecer uma ligação entre o passado, presente e futuro. Em outras palavras, eles garantem a continuidade da nação no tempo ${ }^{11}$ (Gonçalves, 1988, p. 265).

A política de preservação patrimonial desenvolvida nos anos de 1930, que procura estabelecer pontes entre o passado nacional, mesmo antes de existir a nação, e o presente autoritário nas décadas em que vigorou o Estado Novo, criou práticas de seleção, preservação e manutenção de memórias históricas que foram atribuídas à nação brasileira e que foram estendidas pelas décadas seguintes (Chuva, 2009; Gonçalves, 1988).

Quanto ao processo de tombamento efetuado em Cabo Frio, percebe-se o discurso da preservação dos bens edificados pelo DPHAN, na vasta correspondência entre o DPHAN, Prefeitura Municipal, Procuradoria da República no Estado do Rio de Janeiro, Mitra Diocesana e Ordem Terceira, na necessidade de proteção dos bens devido à ameaça do crescimento urbano desordenado ${ }^{12}$.

As narrativas nacionais sobre patrimônio cultural estão estruturalmente articuladas por essa oposição entre transitoriedade e permanência, sendo que as práticas de resgate, restauração e preservação incidem sobre objetos que podem ser pensados como análogos a ruínas, quando não se constituem literalmente em ruínas. Como tais, esses objetos estão sempre em processo de desaparecimento, ao mesmo tempo em que provocando uma permanente reconstrução. Esse interminável jogo entre desaparecimento e reconstrução é que move as narrativas sobre patrimônio cultural em sua busca por autenticidade e redenção (Gonçalves, 1996, p. 28).

O discurso da perda é um argumento muito utilizado pelos técnicos do IPHAN para justificar os processos de tombamento efetuados em Cabo Frio, a partir de uma apropriação desses bens por meio do Estado, que assume a tarefa de guardião de uma memória edificada, no intuito de preservar esses fragmentos do passado para protegê-los da transitoriedade que esses objetos estão sujeitos, seja por meio das intempéries do tempo, da falta de cuidado por parte de particulares ou do poder público, dos desvios de finalidades e descaracterização dos mesmos, transformando-os em referenciais simbólicos coletivos.

Nessa perspectiva, o presente, assim como tudo o que é espacialmente próximo, aparecerá corroído por um processo de perda oposto aquela situação original - distante no tempo ou no espaço definida por coerência, integridade e continuidade. Os efeitos desse esquema de pensamento em termos de práticas envolvendo os chamados patrimônios culturais será o de desenvolver um interminável trabalho de resgaste, restauração e preservação de fragmentos, visando estabelecer uma continuidade com aquela situação originária (Gonçalves,1996, p. 23).

Em correspondência ao Procurador da República no Estado do Rio de Janeiro, em 1961, o diretor do DPHAN, Rodrigo Melo Franco de Andrade, relatou a preocupação com construções irregulares na contiguidade e na vizinhança do Convento e Igreja de Nossa Senhora dos Anjos em Cabo Frio, solicitando providências para que o problema fosse solucionado ${ }^{13}$.

Senhor Doutor Procurador:

Havendo sido executadas, com infração flagrante da legislação federal em vigor, diversas construções 
de feição equivalente a favela, na contiguidade e na vizinhança imediata do Convento e Igreja de N. Sra. dos Anjos, em Cabo Frio, - monumento inscrito nos Livros do Tombo, tal como o comprova a certidão anexa -, venho solicitar empenhadamente as valiosas providências da alçada de V.Exa. junto às autoridades públicas competentes do Estado e do Município, a fim de serem removidas as mencionadas construções e, bem assim, assegurada a proteção eficaz do monumento contra a ocorrência de novas intrusões semelhantes (Processo, n 447-T-51, p. 22).

Para construção de uma memória nacional em Cabo Frio, a justificativa processual também aponta para a ameaça material à existência desses bens e a necessidade de proteger esses monumentos para as gerações vindouras. Analisando essa vasta documentação, a partir de dezenas de correspondências, ofícios, telegramas e certidões, percebemos que, inicialmente, os interesses distintos do DPHAN, da Prefeitura Municipal e da Igreja Católica confluíam no sentido da necessidade de preservação dos bens selecionados para tombamento.

A construção dos patrimônios também esteve permanentemente ligada à tentativa de "salvar da destruição" bens móveis e imóveis que passaram a receber proteção jurídica com este fim. Os órgãos de preservação, através de aparatos jurídicos, tentaram garantir às novas gerações uma espécie de "herança" através de impedimentos legais de destruição, modificação e novas construções (Aguiar, 2015, p. 87).

Para o DPHAN, a urgência no tombamento estava relacionada ao elevado grau de abandono desses bens e à ameaça que o crescimento desordenado da Cidade de Cabo Frio poderia trazer para a preservação dessa memória, entendida pela autarquia estatal, como de interesse nacional.

Na documentação processual, consta um ofício de no 38, de 6 de março de 1978, da Prefeitura de Cabo Frio. No documento, o Chefe do Departamento de Turismo ${ }^{14}$, solicita informações sobre o tombamento efetuado pelo IPHAN, para que fosse efetuada a divulgação, proteção e conscientização da população fixa e flutuante da cidade em defesa do patrimônio histórico local.

Percebemos, por esse ofício, indícios por parte da administração municipal no contexto da década de 1970, isto é, a pretensão de desenvolver uma política de conscientização e de preservação do patrimônio histórico local junto à população da cidade e a seus visitantes, por intermédio de ações de caráter informativo. Para isso, a recorrência à figura de Marcio Werneck da Cunha, intelectual local, ocupante de funções na área da cultura e turismo em diferentes administrações municipais, tendo o mesmo uma vasta produção sobre a história de Cabo Frio ${ }^{15}$.

Em resposta ao ofício municipal, Renato Soeiro, Diretor Geral do IPHAN, enviou para o chefe do departamento de turismo de Cabo Frio, certidões expedidas pelo instituto, com as informações pertinentes ao tombamento do Convento, da Igreja Nossa Senhora dos Anjos e do Forte São Mateus ${ }^{16}$.

Interessante percebermos que, entre a ação de patrimonialização nos anos de 1950 e a década de 1970, período em que o órgão municipal responsável pelo turismo solicita a autarquia federal responsável por delimitar, selecionar os bens edificados que receberão a chancela de Patrimônio histórico, acontece a transformação desses objetos em lugares de memória (Nora, 1993).

Os lugares de memória são, antes de tudo, restos. A forma extrema onde subsiste uma consciência comemorativa numa história que a chama, porque ela a ignora. É a desritualização de nosso mundo que faz aparecer a noção... Museus, arquivos, cemitérios e coleções, festas, aniversários, tratados, processos verbais, monumentos, santuários, associações, são os marcos testemunhas de uma outra era, das ilusões da eternidade (Nora, 1993, pp. 12-13).

A transformação desses lugares de memória do período colonial em arquivos de certa temporalidade procura criar laços de um passado remoto com o presente. Isso ocorre por meio desses semióforos de 
um tempo passado, escolhido pelo IPHAN para ser a representação de um pretérito que não atende mais às características originais pelo qual foi elaborado, e sim uma despersonalização de suas funções e uma ressignificação desses objetos intermediados por uma memória transformada. Ressalta-se, aqui, que essa mudança procura criar laços de identidade entre elementos da história local com a narrativa histórica nacionalista que vigorava no período (Nora, 1993).

Para a Prefeitura, a preservação passava pela possibilidade de ter uma maior visibilidade frente às esferas estaduais e federais de poder. E, graças à relevância desses bens locais, poderia talvez viabilizar recursos para cidade, além de também ser um vetor para o incremento do turismo, visto que o tombamento, apesar de estar embasado em edificações de pedra e cal, ainda tinha o caráter paisagístico de preservação desses bens a serem tombados.

O problema da escassez de verbas para o DPHAN foi uma realidade que atravessou por décadas a autarquia estatal responsável pela política preservacionista nacional, bem como atrasou a implementação de ações de cunho preservacionista em Cabo Frio e outras localidades, apesar das tentativas de buscar parceria com o poder público municipal em ações de restauro (Aguiar, 2016).

Na documentação que trata do processo de tombamento no 0447-T-51, consta uma notificação de no 775, de 22 de novembro de 1956, do DPHAN para o Ministro Provincial da Imaculada Conceição. No documento, há a informação sobre o tombamento do Convento e da Igreja Nossa Senhora dos Anjos, por meio da inscrição no livro de Tombo $n^{\circ} 3$, com a denominação de bem de arquitetura religiosa, pertencente à Província da Imaculada Conceição.

Passados dois anos da notificação sobre o tombamento da igreja e do convento, houve a presença da notificação no 806, de 26 de novembro de 1958, em que o DPHAN informa ao Ministro Provincial Franciscano a ampliação do tombamento das antes aludidas áreas, em que teria agora como acréscimos a capela, cemitério da ordem 3a de São Francisco, cruzeiro em frente ao Convento e a Igreja de Nossa Senhora dos Anjos, conforme inscrição do livro do tombo das Belas Artes.

Nota-se, a partir dessas duas notificações, a preocupação com a preservação de imóveis religiosos, compreendidos entre o Convento e a Igreja Nossa senhora dos Anjos. Posteriormente, o tombamento estendeu a toda área próxima ao Convento, incluindo o Morro da Guia e a capela presente no alto do morro.

Como podemos ainda notar, há uma preocupação com a preservação do bem edificado, considerando se tratar de uma arquitetura religiosa de caráter colonial, isto é, o foco dos arquitetos e técnicos do IPHAN, responsáveis por salvaguardar esse bem, mostrando a perspectiva da época em manter bens ligados ao passado colonial e valorizados a partir de suas características arquitetônicas (Chuva, 2009; Gonçalves, 1996).

Em 1961, foi expedido para o Procurador da República no Estado do Rio de Janeiro um ofício de no 1796, em que é relatada a construção de habitações irregulares na área contígua e vizinha ao Convento, sendo denominadas de feição equivalente à favela. Segundo o documento, essas construções comprometeriam os bens tombados naquela localidade. Em razão disso, são solicitadas providências às autoridades competentes para resolução desse

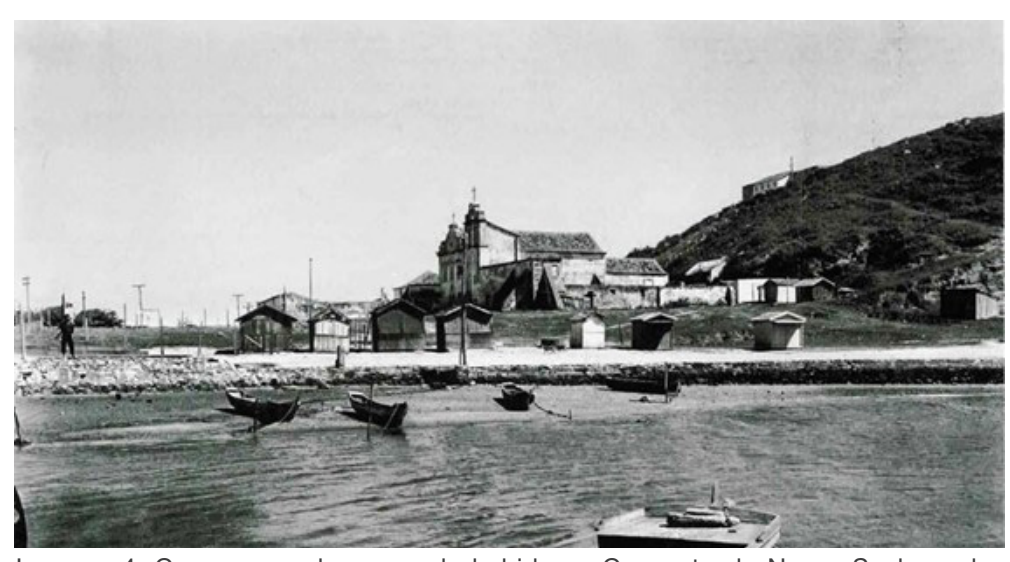

Imagem 4. Canoas com barracas de bebidas e Convento de Nossa Senhora dos Anjos ao fundo em 1958.

Fonte: [http://www.cantinhodasideias.com.br/2014/04/cabo-frio-homenagemwolney-teixeira-de.html]. 
problema, entendendo que fossem asseguradas a proteção eficaz, assim como medidas para conter a ocorrência de novas intrusões. Além da notificação, foi encaminhada em anexo uma certidão, comprovando a inscrição e o tombamento dos bens relatados.

Depois de décadas de abandono e intensas negociações entre a Mitra Diocesana e o DPHAN, será celebrado um acordo no dia 12 de março de 1968, em que é assinado o convênio para criação e instalação de um museu de arte religiosa e tradicional nas ruínas do Convento Nossa Senhora dos Anjos, cedido pelo período de 50 anos. Tal medida permitiu, com recursos provenientes da esfera federal, a sua revitalização, manutenção e administração do espaço.

Além da recuperação material do espaço cedido pela Igreja Católica para a criação do MARTH, o DPHAN se comprometeu a montar expedições temporárias e permanentes no espaço museológico, instalar uma biblioteca especializada e um arquivo histórico regional, além de promover cursos, concertos de arte sacra e autos ou peças de caráter religioso.

Em 12 de fevereiro de 1974, um aditivo ao convênio celebrado entre a Mitra Diocesana de Niterói e o DPHAN em que será anexado ao museu que será instalado no convento a Igreja de Nossa Senhora dos Anjos que está anexa às instalações do convento. A principal justificativa para a preservação está a importância na preservação dos retábulos e do altar que orna a referida Igreja, considerando que poderiam ser de expressivo valor histórico e arquitetônico nacional.

As partes interessadas no presente instrumento de cessão consideram como justificativa primordial desse ato a verificação de que o edifício da Igreja do Convento de Nossa Senhora dos Anjos constitui, por seus atributos arquitetônicos e principalmente pela suntuária que orna seu interior, composta pelo conjunto de retábulos dos atlares mór e colaterais que são obras de talha do século XVII de fino lavor, bem como pela existência do silhar de azulejos policromados que revestem os flancos das paredes da nave e da capela-mor e as imagens que nela se encontram, e que por tais característicos o monumento em causa se afirma como um dos mais expressivos do acervo histórico e artístico nacional (Processo nº 0447-T-51, 1951, pp. 32-33).

O aditivo será celebrado pelo Arcebispo Dom Antonio de Almeida Morais Júnior e pelo Diretor em exercício do DPHAN, o Arquiteto Renato de Azevedo Duarte Soeiro. Assim como no acordo celebrado em 1968, todas as responsabilidades de manutenção, restauro e ações museológicas e educativas a serem desenvolvidas pelo museu de arte sacra devem ser de atribuição da instituição.

Percebemos claramente que a justificativa para a celebração desse acordo passou pela perspectiva preservacionista da época, procurando selecionar, catalogar e enquadrar uma memória histórica, por meio de bens patrimoniais coloniais edificados, relevantes do ponto de vista arquitetônico. Isso mostra mais uma vez o papel desses profissionais como determinante na escolha do que deve ser preservado e considerado patrimônio histórico (Chuva, 2009; Aguiar, 2016).

Em 1951, o SPU ${ }^{17}$ consulta o DPHAN a respeito do interesse desse órgão nas ruínas do Forte São Matheus. Em resposta, o Departamento de Patrimônio confirma o interesse e afirma que a preservação do forte e do seu entorno conhecido como "ponta do forte" é de importância histórica e paisagística e, por esse motivo, deve ser inscrita no livro do tombo.

O Forte São Matheus foi tombado também por meio do processo no 0447-T-51. E, semelhante ao ocorrido com o Convento e a Igreja, com o passar dos anos o crescimento desordenado da cidade, a negligência do poder público municipal em garantir que a área do Forte não sofresse descaracterização com a construção de prédios, casa e hotéis nos arredores, acabou levando o DPHAN a ampliar o tombamento para o penedo em que a construção estava assentada, assim como a praia em um raio de 500 metros, traçada a partir do centro geométrico do Forte. 
Essa ampliação ocorreu a partir da criação de um novo processo de tombamento, o de no 757-T-65, atrelado ao processo original, estendido pelas décadas seguintes, devido a diversos problemas entre o DPHAN, a prefeitura municipal e proprietários de casas e terrenos na cidade.

\section{Considerações finais}

As políticas de preservação patrimoniais fazem parte de um projeto de atribuição de valores que permitem perceber que o processo de seleção de bens tombados na cidade de Cabo Frio obedeceu, considerando a época em que foram realizados, a critérios de escolha que estavam dentro de uma lógica do corpo técnico do IPHAN. Em outras palavras, priorizou-se a seleção de bens edificados ligados ao passado colonial, isto é, em suas narrativas os técnicos pretenderam ligar esses fragmentos do passado com o presente, dentro de uma perspectiva de valorização de um discurso nacionalista.

Ao longo do estudo, percebemos que os processos de tombamento têm como intuito produzir uma inteligibilidade histórica a partir da memória edificada e ligada ao passado colonial português, que sofreu um enquadramento de memória, por meio da reificação desses bens patrimoniais. Despersonificados de suas características originais, tais bens tornaram-se lugares de memória a partir da narrativa intelectual produzida pelos membros do instituto do patrimônio histórico que elegeu locais, bens e memórias atreladas a esses espaços como locais de produção de sentido histórico.

Nesse sentido, acreditamos que a política de preservação restringiu-se ao tombamento e à fiscalização dos bens imóveis, sem maior envolvimento da sociedade civil organizada, em função de uma determinada concepção de política de preservação vigente à época, que elencava ao IPHAN e aos técnicos ligados ao instituto a atribuição de elegerem os monumentos que seriam reverenciados como mantenedores da memória local e que estivessem elencados a uma narrativa histórica que entendia a história local como um apêndice ou complemento da dita história nacional. Tais desdobramentos, cumpre ressaltar, demonstram uma falta de protagonismo da participação efetiva da população, bem como do poder público cabofriense nos processos decisórios sobre o tombamento e de enquadramento da memória relacionada à história da cidade.

O estudo da política de preservação patrimonial local permite perceber disputas de memória entre os diversos agentes envolvidos no processo. Entende-se aqui que tais controvérsias vão desde os técnicos do IPHAN, passando pelo poder público municipal, setores da sociedade civil, empresários, a outros com diferentes interesses socioeconômicos. As polêmicas se devem às transformações sofridas pelo crescimento da cidade no decorrer do século XX e à expansão de atividades econômicas, como as do turismo e do setor imobiliário, resultando em situações conflituosas acerca da preservação do patrimônio histórico local, bem como na necessidade de intervenção do poder público federal, por intermédio do IPHAN, este que tem a chancela de selecionar, catalogar e promover políticas de proteção patrimonial.

É necessário perceber, portanto, que as políticas de preservação fazem parte de um projeto de atribuição de valores, de disputas de memórias. Esses processos trazem, em seu bojo, tensões por trás dos tombamentos efetuados na cidade, permitindo realizar práticas de educação em patrimônio, distintas das tradicionais. Em outros termos, cumpre ressaltar, essas ações nos permitem observar na localidade os interesses da população por elementos da história local, capazes de ser valorizados, e não apenas o ponto de vista do IPHAN, do poder público ou de especialistas no campo das Ciências Humanas. 


\section{NOTAS}

${ }_{1}^{1}$ A perspectiva de tombamento aplicada em Cabo Frio, por meio dos processos de $n^{\circ}$ 0447-T-51 e o 0757-T65 , está dentro do conceito utilizado pelos técnicos do SPHAN que, à época, entendia-se o patrimônio histórico e artístico nacional como o "conjunto de bens móveis e imóveis existentes no país e cuja conservação seja de interesse público, quer por sua vinculação a fatos memoráveis da história do Brasil, quer por seu excepcional valor arqueológico ou etnográfico, bibliográfico ou artístico". Sendo também classificados. como patrimônio, "monumentos naturais, bem como sítios e paisagens que importe conservar e proteger pela feição notável com que tenham sido dotados pela natureza ou agenciados pela indústria humana" (Gonçalves, 1996, p. 68).

2 Informações obtidas por meio dos processos de tombamento efetuados pelo IPHAN em Cabo Frio: 0447-T-51-Conjunto arquitetônico e paisagístico do Morro da Guia e da Ponta do Forte, e 0757-T-65 Conjunto paisagístico de Cabo Frio.

${ }^{3} \mathrm{O}$ autor toma de empréstimo o conceito de lugar de memória a partir das ideias de Pierre Norra, utilizando-se como base um artigo de Pesavento, 2002, p. 29.

${ }^{4}$ A perspectiva de "preservar tudo", como marca de um passado glorioso, é muito utilizada quando a preservação é vinculada ao discurso nacionalista. Por sua vez, este discurso foi muito influente nas questões de patrimônio, além de modificar-se ao longo do tempo, de acordo com a história de cada nação, sendo muito utilizado quando percebemos, no caso do Brasil, a valorização de bens edificados como representantes de fragmentos de uma história nacional, e que a preservação desses bens estaria vinculada a uma narrativa histórica nacionalista (Chuva, 2009; Gonçalves, 1996).

${ }^{5}$ Nesse artigo, Pollak cita as disputas de memória entre na Europa em torno da Memória de Stalin no contexto de desestalinização ocorrida no século XX e os diferentes usos e silenciamentos dessa memória (Pollak, 1989, pp. 4-8).

${ }^{6}$ Como o IPHAN ao longo de sua trajetória teve diversas denominações, a fim de evitar a utilização repetida dessas variadas siglas no decorrer do artigo, utilizaremos a perspectiva adotada por Leila Bianchi Aguiar, que elucida de maneira breve essas transformações: "Optamos por chamar de IPHAN a agência federal de preservação criada como Serviço do Patrimônio Histórico e Artístico Nacional (SPHAN) em 1937. Em 2 de janeiro de 1946, o Decreto-Lei 8.534 transformou o Serviço em Diretoria (DPHAN). Em 27 de julho de 1970, o Decreto no 66.967 transformou a DPHAN em Instituto (IPHAN). Em 26 de novembro de 1979, o Congresso Nacional aprovou a Lei no 6.757, criando a Fundação Nacional Pró-Memória, órgão operacional do IPHAN. Um resumo cronológico com as principais transformações sofridas pela agência pode ser encontrado na Revista do Patrimônio Histórico e Artístico Nacional, n²2, 1987, p. 343" Agiuilar (2016, p. X).
7 Entendemos o tombamento a partir da perspectiva de José Reginaldo Gonçalves, como um ato de incorporação de um bem ao patrimônio histórico e artístico nacional. Sendo o tombamento um importante instrumento legal usado para que o Estado se aproprie dos bens culturais que integram o chamado patrimônio nacional. Uma vez tombado, o referido bem é inscrito e um ou mais livros do Tombo, classificados em: Livro do Tombo Arqueológico, Etnográfico e Paisagístico; Livro do Tombo Arqueológico; Livro do Tombo de Belas Artes e o Livro do Tombo das Artes aplicadas (Gonçalves, 1996, p. 66).

${ }^{8}$ As informações pertinentes às fontes utilizadas foram obtidas no Arquivo Noronha Santos: Arquivo Central do IPHAN, com auxílio do aplicativo Wetransfer que transferiu os processos digitalizados. Processos de tombamento em Cabo Frio: 0447-T-51 Conjunto arquitetônico e paisagístico do Morro da Guia e da Ponta do Forte. 0757-T-65 Conjunto paisagístico de Cabo Frio.

${ }^{9}$ Rodrigo Melo Franco de Andrade foi nomeado diretor do SPHAN em 1937 pelo ministro da Educação Gustavo Capanema e ocupou o cargo até 1967, participando da criação, estruturação e sistematização das políticas de preservação patrimoniais do Brasil ao longo de três décadas. Recuperado de [http://portal.iphan.gov.br/ noticias/detalhes/481/vida-e-obra-rodrigo-melo-francode-andrade-1898-\%E2\%80\%93-1969]. Consultado 2602-2017].

${ }^{10}$ Ofício $n^{\circ} 780$, da Diretoria do Patrimônio Histórico e Artístico Nacional, assinado pelo diretor Rodrigo Melo Franco de Andrade (Processo n 447-T-51, p. 5).

${ }^{11}$ Sobre a transformação e a utilização de relíquias e monumentos em bens culturais, Gonçalves, 1988.

12 Processo: 0447-T-51: ofício $\mathrm{n}^{\circ} 70$ do DPHAN para prefeitura de Cabo Frio de 1951; ofício n 89/51 da Prefeitura de Cabo Frio para o DPHAN; correspondência para vigário da paróquia de Cabo Frio em 1956; telegrama do DPHAN para a Mitra Diocesana em Niterói e resposta da mesma no ano de 1956; notificação $n^{\circ}$ 775 do DPHAN para o Ministro Provincial Franciscano de 1956; notificação $n^{\circ} 806$ do DPHAN para o Ministro Provincial Franciscano de 1958; ofício no 1796 do DPHAN para o Procurador da República no Estado do Rio de Janeiro em 1961.

${ }^{13}$ Processo 0447-T-51: ofício n 1796 do DPHAN para o Procurador da República no Estado do Rio de Janeiro em 1961.

${ }^{14} \mathrm{O}$ ofício municipal foi assinado por Márcio Werneck da Cunha, indivíduo que, além de ocupar diversos cargos na esfera municipal entre as décadas de 1970 e 1990, no campo do turismo e da cultura local, também foi responsável pela elaboração de diversos estudos sobre a história de Cabo Frio e da região. 
${ }^{15}$ Para maiores informações sobre a biografia e produção historiográfica de Márcio Werneck da Cunha. [https:// acervomarciowerneck.com.br/curriculo/]. Consultado [26-02-2017].

${ }^{16}$ Ofício nº 605 do IPHAN, de 14 de março de 1978.

17 Serviço de Patrimônio da União (SPU), criado em 1854 a partir do Decreto $n^{\circ} 1318$, que regulamentou a "Repartição Geral de Terras Públicas". O SPU foi a primeira instituição incumbida de organizar a questão fundiária no país. Desde então, o órgão passou por diversas reformulações, até a configuração atual, como integrante da estrutura do Ministério do Planejamento, Orçamento e Gestão (MP), a quem compete a administração do patrimônio imobiliário da União [ http://www.planejamento.gov.br/assuntos/patrimonioda-uniao/noticias/secretaria-do-patrimonio-da-uniaocompleta-162-anos-neste-sabado]. Consultado [26-022017].

\section{FONTES}

Arquivo Noronha Santos: Arquivo Central do IPHAN. Processos de tombamento em Cabo Frio: As informações obtidas dos processos de tombamento foram cedidas pelo Arquivo Central do IPHAN, com auxílio do aplicativo Wetransfer que transferiu os processos digitalizados. 0447-T-51 Conjunto arquitetônico e paisagístico do Morro da Guia e da Ponta do Forte. 0757-T-65 Conjunto paisagístico de Cabo Frio. 


\section{REFERÊNCIAS BIBLIOGRÁFICAS}

Aguiar, L. B. (2015). Reflexões sobre estados nacionais e a criação das agências de preservação dos patrimônios culturais. Revista Conhecimento \& Diversidade, Niterói, n० 13, 79-89.

Aguiar, L. B. (2016). Desafios, permanências e transformações na gestão de um sítio urbano patrimonializados: Ouro Preto, 1938-1975. Revista Estudos Históricos, 29(57), 87-106.

Beranger, A. (2003). Dados Históricos de Cabo Frio (3a Ed.). Cabo Frio: Comissão Executiva do Projeto Cabo Frio 500 Anos de História.

Candau, J. (2014). Memória e identidade. São Paulo: Contexto.

Catroga, F. (2001). Memória, história, historiografia. Coimbra: Quarteto.

Chuva, M. R. R. (2009). Os arquitetos da memória: Sociogênese das práticas de preservação do patrimônio cultural no Brasil (1930-1940). Rio de Janeiro: UFRJ.

Costa, F. S. C. (2009). La cultura histórica. Uma aproximación diferente a la memoria coletiva. Passado y memoria. Revista de Historia Contemporánea, nº 8, 267286.

Cunha, M. W. da. (2017). Relatório sobre monumentos e espaços culturais em Cabo Frio. Recuperado de [http://acervomarciowerneck.com.br/cmdownloads/ relat \% C $3 \%$ B 3 rio-sobre-monumentos-eespa\%C3\%A7os-culturais-de-cabo-frio/]. Consultado [21-07-2017].

Daher, A. (2012). Objeto cultural e bem patrimonial: representações e práticas. Revista do Patrimônio Histórico e Artístico Nacional, $n^{\circ} 34,113-130$.

Gonçalves, J. R. S. (1996). A Retórica da perda: os discursos do patrimônio cultural no Brasil. Rio de Janeiro: Editora: UFRJ; IPHAN.

Gonçalves. J. R. S. (1988). Autenticidade, memória e ideologias nacionais: $O$ problema dos patrimônios culturais. Estudos Históricos, 1(2), 264-275.

Guimarães, M. L. S. (2012). História, memória, patrimônio. Revista do Patrimônio Histórico e Artístico Nacional, $n^{\circ} 34$, 91-112.

Hartog, F. (2013). Regimes de historicidade. Presentismo e experiências do tempo. Belo Horizonte: Autêntica.

Huyssen, A. (2000). Seduzidos pela memória. Rio de Janeiro: Aeroplano.

IPHAN. Informações sobre bens tombados em Cabo Frio. Recuperado de [http://portal.iphan.gov.br/pagina/ detalhes/872]. Consultado [26-02-2017].
Norra, P. (1993). Entre memória e história: a problemática dos lugares. Projeto História (Vol. 10, pp. 7-28). Recuperado de [http://revistas.pucsp.br/index.php/ revph/article/view/12101/8763]. Consultado [20-012017].

Pesavento, S. J. (2002). Memória, história e cidade: lugares no tempo, momentos no espaço. ArtCultura, 4(4).

Pesavento, S. J. (2005). Cidade, espaço e tempo: reflexões sobre a memória e o patrimônio urbano. Cadernos do LEPAARQ - Textos de Antropologia, Arqueologia e Patrimônio, II(4). Pelotas, Rio Grande do Sul: Editora da UFPEL.

Pollak, M. (1989). Memória, Esquecimento, Silêncio. Revista Estudos Históricos, 2(3), 3-15.

Pollak, M. (1992). Memória e identidade social. Revista Estudos Históricos, 5(10), 200-212.

Poulot, D. (2012). A razão patrimonial na Europa do século XVIII ao XXI. Revista do Patrimônio Histórico e Artístico Nacional, $\mathrm{n}^{\circ}$ 34, pp. 27-44.

Ribeiro, F. M. F, \& Moreira, L. G. S. (2017). Cabo Frio: 400 anos de história, 1615-2015. Brasília: IBRAM.

Ribeiro, W. C., \& Zanirato, S. H. (2008). Ordenamento jurídico para a proteção do patrimônio natural no Brasil. Revista de História, $\mathrm{n}^{\circ} 158$, pp. 277-300. Recuperado de [http://www.revistas.usp.br/revhistoria/article/ view/19082]. Consultado [20-07-2017].

Tomaz, P. C. (2010). A preservação do patrimônio cultural e sua trajetória no Brasil. Recuperado de [http://www. revistafenix.pro.br/PDF23/ARTIGO 8 PAULO CESAR TOMAZ_FENIX_MAIO_AGOSTO_2010.pdf ]. Consultado [14-11-2016]. 